\title{
LA IMAGEN DE LA MUJER EN LOS MEDIOS. EXIGENCIAS DEL PRINCIPIO DE IGUALDAD
}

\author{
MARÍA SALVADOR MARTÍNEZ \\ Universidad Nacional de Educación a Distancia (UNED)
}

Fecha de recepción: 8-9-2008.

Fecha de aceptación: 30-9-2008.

\section{El principio de igualdad en el ámbito de la comunicación}

Como se sabe, el principio de igualdad, reconocido en diversos artículos de nuestra Constitución, es el principio estructural más importante de todo el ordenamiento jurídico e impone exigencias a la actuación de todos los poderes públicos en todas las esferas y respecto de todas las personas y grupos de los que las éstas forman parte, así como también de la actuación de los particulares entre sí1.

Siendo uno de los principios estructurales, sin embargo, la determinación del contenido del principio de igualdad no es una tarea sencilla ${ }^{2}$. No obstante, desde el punto de vista de las exigencias que impone a la actuación de los poderes públicos, sí es claro que el citado principio contiene un doble mandato: el mandato de la igualdad formal y el mandato de la igualdad material.

1. Arts. 1.1, 9.2 y 14 de la Constitución Española (en adelante, CE).

2. La bibliografía sobre el principio de igualdad es muy extensa. Las principales obras de referencia y de mayor claridad expositiva que se pueden consultar son: DíEZ PICAZO, Luis $\mathrm{M}^{\mathrm{a}}$.: Sistema de derechos fundamentales, Navarra, Thomson-Civitas, 2005 ( $2^{\mathrm{a}} \mathrm{ed}$.), pp. 191-215; GARCÍA MORILLO, Joaquín: «La cláusula general de igualdad», en L. López Guerra, E. Espín y otros, Derecho Constitucional, Vol. I, Valencia, Tirant lo Blanch, 2003 (6 ${ }^{a}$ ed.); RUBIO LlORENTE, Francisco: «La igualdad en la jurisprudencia del Tribunal Constitucional. Introducción», y «Juez y ley desde el punto de vista del principio de igualdad», en La Forma del Poder, Madrid, CEPC, 1997; también «Igualdad», en M. Aragón Reyes (coord.): Temas Básicos de Derecho Constitucional, Tomo III, Madrid, Cívitas, 2001; y Salvador Martínez, María: «La igualdad», en S. Sánchez González, Dogmática y Práctica de los Derechos Fundamentales, Valencia, Tirant lo Blanc, 2006, pp. 95-123. 
El primero impone la obligación de dar un trato no discriminatorio (es decir, igual o, según el caso, diferente, siempre que sea justificado). El segundo mandato impone objetivos que se han de alcanzar, concretamente, obliga a tener en cuenta las desigualdades que existen en la realidad y a intervenir para corregirlas con objeto de lograr una igualdad real y efectiva. No se trata de mandatos contradictorios ni incompatibles, aunque pudiera parecerlo o alguna vez se hayan presentado así, sino de carácter complementario. Por último, el principio de igualdad contiene, además de los dos mandatos mencionados, una «prohibición de ciertas discriminaciones», entre ellas, «la discriminación por razón de sexo», la discriminación entre hombres y mujeres. Esto significa que la Constitución reconoce la discriminación estructural que existe de las mujeres y, en consecuencia, impone la obligación de trato igual entre hombres y mujeres, exigiendo una justificación muy rigurosa si se impone un trato diferente que perjudique a la mujer, y, por otro lado, establece la obligación de adoptar las medidas que sean necesarias para superar esa discriminación estructural y lograr una igualdad real y efectiva, incluyendo las medidas que introduzcan un trato diferente favorable a la mujer y que, si está justificado (si es razonable, proporcionado), no se podrá considerar contrario al mandato de la igualdad formal ${ }^{3}$.

Este principio, referido a la actuación de poderes públicos, y con el contenido que hemos visto, se proyecta sobre todos los ámbitos en los que se desarrolla la vida política y social. Entre ellos, como es obvio, en el ámbito de la comunicación, una esfera de especial trascendencia para lograr la igualdad real y efectiva entre hombres y mujeres, ya que la comunicación está en el origen de la comunidad política. Una sociedad se construye a partir de los elementos que sus miembros ponen en común, de la comunicación que se desarrolla entre ellos. Esos elementos comunes se terminan transformando en las ideas y convicciones de ese grupo social y pasan a ser el fundamento del orden político y jurídico que establezca dicho grupo.

Por eso, si en la comunicación se transmite una imagen de la mujer distorsionada e irreal, en el orden político y jurídico se proyectará esa misma distorsión y las mujeres no podrán ocupar el lugar que les corresponde ni ejercer

3. En concreto sobre la discriminación «por razón de sexo», se puede consultar, entre otras obras generales: FREIXES, Teresa (coord.): Mujer y Constitución en España, Madrid, Centro de Estudios Políticos y Constitucionales, 2000; Balaguer, $M^{a}$ Luisa: Mujer y Constitución. La construcción jurídica del género, Madrid, Cátedra, 2005; VenTURA, Asunción: Las mujeres y la Constitución Española de 1978, Madrid, Instituto de la Mujer, 1999; REY, Fernando: El derecho fundamental a no ser discriminado por razón de sexo, Madrid, McGraw Hill, 1995. 
sus derechos en condiciones de igualdad. La discriminación estructural de la mujer se manifiesta en la imagen que se transmite de ella en los procesos de la comunicación, una imagen no real y equilibrada, sino estereotipada y sexista en la que a la mujer se la encasilla en roles secundarios y subordinados al hombre. Al mismo tiempo, esta imagen distorsionadora contribuye a perpetuar esos roles y la discriminación que traducen. Por eso, a mi juicio, todas las acciones dirigidas a eliminar dicha imagen, y a construir una imagen real y equilibrada de las mujeres y de su papel en la sociedad, son uno de los elementos primeros y principales del mandato de la igualdad real y efectiva entre hombres y mujeres ${ }^{4}$.

Pues bien, la obligación de los poderes públicos de adoptar las medidas necesarias en ese sentido deriva de la Constitución, concretamente, del principio de igualdad (mandato de la igualdad real y efectiva), como ya hemos visto, pero también de otras disposiciones constitucionales: del principio de la dignidad humana y de los derechos fundamentales al honor, intimidad y propia imagen, aplicados todos ellos a la mujer; y también de las normas que atribuyen a los medios de comunicación, y especialmente a los medios públicos, la función constitucional de servir a la garantía de la formación de la opinión individual y pública, y a la garantía de los derechos fundamentales, incluidos los derechos antes citados.

El cumplimiento de la citada obligación constitucional corresponde, en primer lugar, al legislador, que debe aprobar las medidas legislativas que considere necesarias para ello. En este sentido, se puede distinguir una primera etapa caracterizada por la inexistencia de disposiciones legales o por la insuficiencia de las disposiciones existentes, en las que el legislador se limitaba a reproducir los principios constitucionales, sin realizar un verdadero desarrollo de los mismos. En los últimos años, sin embargo, se ha producido un cambio importante que marca el inicio de una nueva etapa en la que el legislador ha adoptado una actitud mucho más activa, desarrollando los principios

4. En esta materia, se pueden consultar los trabajos jurídicos de BALAGUER, $M^{a}$ Luisa: $L a$ mujer y los medios de comunicación, Málaga, Ed. Arguval, 1985; y «La regulación y el control de la publicidad en el ordenamiento jurídico constitucional español», Boletín de la Facultad de Derecho de la UNED, 21 (2003), pp. 133-165; GONZÁLEZ ENCINAR, José J. y SALVADOR MARTínEZ, María: «La mujer y los derechos de la comunicación», en T. Freixes (coord.): Mujer y Constitución en España, op. cit., pp. 669-693; y SALVADOR MARTínEZ, María: «Mujer, derechos fundamentales y comunicación», en J. Benavides, D. Alameda, E. Fernández y N. Villagra (coords.), Nuevos retos y perspectivas de investigación en la comunicación, Madrid, Fundación General de la Univ. Complutense, 2005, pp. 281-299.

5. Art. 10 CE (dignidad humana), art. 18 (derecho al honor, intimidad y propia imagen) y arts. 1.1 y 20 (principio democrático y regulación de los derechos y medios de comunicación).

Feminismo/s 12, diciembre 2008, pp. 185-202 
constitucionales y adoptando medidas concretas para eliminar las discriminaciones existentes en el ámbito de la comunicación. La aprobación de las Leyes de Igualdad y de las Leyes contra la violencia de Género, tanto a nivel nacional como autonómico, así como las reformas introducidas en algunos Estatutos de Autonomía son buena prueba de ello.

A los restantes poderes públicos, por su parte, les corresponde el cumplimiento de las disposiciones y medidas legislativas, y la tarea de supervisión y control para garantizar dicho cumplimiento. Y aquí está, a mi juicio, la gran tarea aún pendiente.

Finalmente, hay que advertir que las exigencias que derivan del principio de igualdad y de las restantes disposiciones constitucionales mencionadas, en el ámbito de la comunicación, no se refieren sólo a la imagen que los medios transmiten de la mujer, sino también a la necesidad de fomentar el ejercicio de las libertades de expresión e información por las mujeres, al acceso en condiciones de igualdad a los medios (acceso a la profesión, a los órganos de decisión de los medios, a la programación), al acceso en condiciones de igualdad a la información, educación y cultura, etc. Entre ellas, sin embargo, destaca por su importancia la exigencia de garantizar que los medios transmitan una imagen de la mujer real y equilibrada, por las razones antes señaladas, y al análisis de la misma se dedican las siguientes páginas ${ }^{6}$.

\section{La imagen de la mujer en los medios}

Para mejor analizar los problemas que plantea la imagen de la mujer en los medios, así como la intervención que los poderes públicos han realizado al respecto, conviene distinguir entre los medios escritos, los audiovisuales y la publicidad.

\subsection{Los medios escritos}

Como en todos los medios, la imagen de la mujer que se transmite en los medios escritos varía según el tipo de publicación, siendo muy diferente la imagen que pueden transmitir los periódicos de la que transmiten las revistas llamadas «femeninas». Lo que resulta común a todos los medios escritos es el

6. Sobre las exigencias relativas a estos otros aspectos se pueden consultar: GONZÁLEZ ENCinAR, José J. y SAlVAdOR MARTíneZ, María: op. cit., pp. 669-677; y SALVAdOR MARTíNEZ, María: «Mujer, derechos fundamentales...», op. cit., p. 281-288. 
sexismo del lenguaje, aunque, como es obvio, el uso del lenguaje no es privativo de los medios escritos ${ }^{7}$.

Frente a eso, hay que advertir que el ámbito de la prensa se caracteriza por la ausencia de normas reguladoras del sector, ya que la Ley de Prensa e Imprenta de 1966 está en su mayor parte derogada y no ha sido sustituida por ninguna ley posterior. Por eso, hasta la aprobación de las Leyes de Igualdad, tanto a nivel nacional como autonómico, no existían disposiciones legales dirigidas a la protección de la imagen de la mujer en los medios escritos. Actualmente, sin embargo, las citadas Leyes establecen, por un lado, que los medios, incluidos los escritos, transmitirán una imagen real de la mujer, sin estereotipos sexistas ${ }^{8}$; y por otro, que los medios no harán un uso sexista del lenguaje, e, incluso, que los poderes públicos deben velar por la erradicación del uso sexista del mismo en los medios de comunicación social mediante campañas de formación e información ${ }^{9}$.

\subsection{La radiotelevisión}

$\mathrm{Al}$ igual que ocurre en los medios escritos, la imagen de la mujer que transmiten los medios audiovisuales depende del tipo de programa. Pero, con carácter general, la radiotelevisión no ofrece una imagen real y equilibrada de los diversos estilos de vida de las mujeres y de su aportación a la sociedad, sino que buena parte de la programación transmite imágenes negativas, estereotipadas,

7. Diversos estudios, entre los que destacan los de la Comisión NOMBRA, demuestran el sexismo y el androcentrismo del lenguaje; sexismo, porque lo femenino no tiene una definición autónoma, sino en función de lo masculino, y porque la mujer no aparece como sujeto autónomo, sino perteneciendo a otro sujeto; y androcentrismo, porque se invisibiliza a las mujeres y lo masculino genérico, la palabra «hombre», representa a la humanidad, ocultando la diferencia sexual existente en la condición humana (AAVV, Lo Femenino y lo Masculino en el Diccionario de la Lengua de la Real Academia Española, Madrid, Instituto de la Mujer, 1998).

8. Arts. 36 y 39 de la LO 3/2007, de 22 de marzo, para la igualdad efectiva de hombres y mujeres; art. 26.1 de la Ley 4/2005, de 18 de febrero, del Parlamento Vasco, de igualdad de hombres y mujeres; art. 15.5 de la Ley 1/2003, de 3 de marzo, de las Cortes de Castilla y León, de igualdad de oportunidades entre mujeres y hombres; art. 37.1.c de la Ley 7/2007, de 4 de abril, del Parlamento de Murcia, para la igualdad entre mujeres y hombres; art. 57.1 de la Ley 12/2007, de 26 de noviembre, del Parlamento de Andalucía, para la promoción de la igualdad de género.

9. Art. 26.3 de la Ley 4/2005, de 18 de febrero, del Parlamento Vasco, de igualdad de hombres y mujeres; art. 39 de la Ley 12/2006, de 20 de septiembre, del Parlamento de las Illes Balears sobre normas reguladoras para la mujer; art. 38 de la Ley 7/2007, de 4 de abril, del Parlamento de Murcia, para la igualdad entre mujeres y hombres; art. 9 de la Ley 12/2007, de 26 de noviembre, del Parlamento de Andalucía, para la promoción de la igualdad de género.

Feminismo/s 12, diciembre 2008, pp. 185-202 
inexactas, violentas, invisibiliza a determinados grupos de mujeres y suele definir a la mujer por su apariencia más que por sus habilidades ${ }^{10}$.

Por eso, con el objeto de proteger la dignidad y la imagen de la mujer en la programación de los medios audiovisuales, las normas del sector han ido evolucionando en el siguiente sentido:

- Las primeras normas reguladoras del sector se limitaron a recoger los principios y derechos constitucionalizados. Así, el anterior Estatuto de la Radio y la Televisión, de 1980, establecía, en su preámbulo, que «la radiodifusión y la televisión... se concibe... como medio capital para contribuir a que la libertad y la igualdad sean reales y efectivas, con especial atención a la protección de los marginados y a la no discriminación de la mujer», y, en su art. 4, consagraba como principios que deben inspirar la actividad de los medios de comunicación social del Estado «el respeto al honor, la fama, la vida privada de las personas y cuantos derechos y libertades reconoce la Constitución» y «el respeto de los valores de igualdad recogidos en el art. 14 de la Constitución ${ }^{11}$. Más tarde, las correspondientes leyes establecieron que esos principios también debían inspirar la actividad del resto de radiotelevisiones, tanto públicas ${ }^{12}$ como privadas $^{13}$.

- En 1994, la conocida Ley de Televisión sin Fronteras, transposición de una directiva comunitaria, fue más allá al establecer que las emisiones de televisión no debían incluir programas ni escenas o mensajes de cualquier tipo que fomentasen la discriminación por motivos de sexo ${ }^{14}$.

- En el mismo sentido, y para dar respuesta al terrible problema de la violencia de género, en 2004 la Ley Orgánica de Medidas de Protección Integral contra la Violencia de Género estableció que los medios de comunicación

10. Vid., entre otros estudios, los de LÓPEz DíEz, Pilar: Representación de género en los informativos de radio y televisión, Madrid, IORTV e Instituto de la Mujer, 2002, p. 39 y ss.; y La violencia contra las mujeres en los medios de comunicación, Madrid, IORTV, 2002 , p. 21 y ss.

11. Ley 4/1980, de 10 de enero, del Estatuto de la Radio y la Televisión.

12. Art. 5 de la Ley 46/83, de 26 de diciembre, reguladora del Tercer Canal de televisión. En las leyes autonómicas reguladoras de la radiotelevisión pública autonómica, por ejemplo, el art. 4.e) de la Ley 6/1999, de 1 de septiembre, del audiovisual de Galicia, establece como principio de la actividad audiovisual «el respeto y la promoción de los valores de igualdad y no discriminación por razón de sexo».

13. Art. 3 de la Ley 10/88, de 3 de mayo, de Televisión Privada; Disp. Adic. $7^{a}$ de la Ley 37/95, de 12 de diciembre, de Telecomunicaciones por Satélite; y art. 6 de la Ley 41/95, de 22 de diciembre, de televisión local por ondas terrestres.

14. Art. 17.1 Ley 25/1994, de 12 de julio, por la que se incorpora al ordenamiento jurídico español la Directiva 89/522/CEE sobre coordinación de disposiciones relativas al ejercicio de actividades de radiodifusión televisiva. 
debían fomentar la protección y salvaguarda de la igualdad entre hombre y mujer, evitando toda discriminación entre ellos ${ }^{15}$.

- Finalmente, ante la ineficacia de las primeras normas del sector y de la Ley de Televisión sin Fronteras, las Leyes de Igualdad aprobadas en los últimos años han dado un paso más allá. Como obligación general para todos los medios de comunicación (públicos y privados) se establece que éstos deben respetar la igualdad entre hombres y mujeres, y evitar cualquier forma de discriminación. En cuanto a los medios públicos, las obligaciones son aún más concretas: los medios de comunicación social de titularidad pública deben velar por la transmisión de una imagen igualitaria, plural y no estereotipada de mujeres y hombres en la sociedad, y promoverán el conocimiento y la difusión del principio de igualdad entre mujeres y hombres; y específicamente, la Corporación RTVE, en el ejercicio de su función de servicio público, debe perseguir en su programación los siguientes objetivos: a) reflejar adecuadamente la presencia de las mujeres en los diversos ámbitos de la vida social; b) utilizar el lenguaje en forma no sexista; c) adoptar, mediante la autorregulación, códigos de conducta tendentes a transmitir el contenido del principio de igualdad; y d) colaborar con las campañas institucionales dirigidas a fomentar la igualdad entre mujeres y hombres y a erradicar la violencia de género ${ }^{16}$.

Estas nuevas leyes, y los mandatos más concretos que contienen, suponen un importante paso adelante, porque proporcionan el fundamento legal necesario para reaccionar ante la transmisión de imágenes estereotipadas, sexistas y discriminatorias. Pero estas leyes exigen como complemento necesario el establecimiento de mecanismos eficaces de supervisión y control de las normas de programación. Sin ellos, el cumplimiento de los mandatos y las obligaciones antes señaladas prácticamente dependerá de la voluntad de los medios de comunicación, y es preciso tener presente que el cumplimiento de dichos mandatos exige a los medios un esfuerzo importante, ya que supone romper con una inercia muy fuerte generada, sobre todo, por la publicidad,

15. Art. 14 LO 1/2004, de 28 de noviembre, de Medidas de Protección Integral contra la Violencia de Género. Con esa misma redacción se recoge este mandato en el art. 3 de la nueva Ley de Radiotelevisión Española (Ley 17/2006, de 5 de junio, de la radio y la televisión de titularidad estatal).

16. Arts. 36 y 37.1 LO 3/2007, de 22 de marzo, de Igualdad, respecto a los medios públicos de ámbito nacional. En el ámbito autonómico, por ejemplo, art. 35 de la Ley 12/2006, de 20 de septiembre, del Parlamento de las Illes Balears; art. 26 de la Ley 4/2005, de 18 de febrero, del Parlamento Vasco, de igualdad de mujeres y hombres; art. 58 de la Ley 12/2007, de 26 de noviembre, del Parlamento de Andalucía, para la promoción de la igualdad de género.

Feminismo/s 12, diciembre 2008, pp. 185-202 
a través de la cual se financian, en mayor o menor medida, todos los medios de comunicación.

Así pues, de cara a establecer un sistema eficaz de supervisión y control de la actividad de los medios de comunicación, en mi opinión, habría que acometer diversas tareas. En primer lugar, reforzar la labor que realizan los Observatorios de Publicidad, como se ha hecho ya a nivel nacional, otorgando al citado observatorio nuevas competencias y ampliando su ámbito de actuación a la programación de los medios. En segundo lugar, fomentando la labor de los Consejos Audiovisuales en este ámbito, ya que los citados Consejos, con amplias competencias en la materia, se han ocupado ya, por ejemplo, de la protección de los derechos de los menores, dictando instrucciones, realizando informes, etc., pero hasta ahora no se han ocupado de la imagen de la mujer en la radiotelevisión. En tercer lugar, exigir a los restantes poderes públicos con competencias de supervisión en la materia, especialmente a los Gobiernos y Administraciones Públicas, el ejercicio de dichas competencias, ya que en algunos casos en los que las facultades de control corresponden a estos órganos, como el de Ley de Televisión Sin Fronteras, el número de expedientes de supervisión tramitados y de sanciones impuestas, comparados con los incumplimientos constantes de dicha Ley, es absolutamente ridículo.

\subsection{La publicidad}

La publicidad es, con mucha diferencia, la actividad frente a la cual los derechos fundamentales de la mujer resultan más vulnerables y vulnerados ${ }^{17}$. En primer lugar, la mujer aparece en los anuncios con mucha más frecuencia que los hombres, un hecho que se explica, por un lado, porque la mujer es la «compradora por excelencia», ya que es la que toma la mayor parte de las decisiones en el ámbito del hogar, y, por otro, porque la publicidad utiliza a la mujer como imagen que incita al consumo. En segundo lugar, la publicidad proyecta una imagen completamente estereotipada y distorsionada de la mujer: el cuerpo femenino se utiliza como reclamo comercial, exhibiéndole

17. Así, la Recomendación 84 (3) del Consejo de Europa, acerca de los principios relativos a la publicidad en televisión, destaca el impacto que ejerce la publicidad en las actitudes y comportamientos del público y la importancia de la imagen de hombres y mujeres proyectada por los medios de comunicación; asimismo recomienda a los Estados cerciorarse del cumplimiento de los principios de publicidad, entre los que se encuentra el respeto de la dignidad e igualdad de todos los seres humanos. La Resolución del Parlamento Europeo, de 6 de octubre de 1997, sobre la discriminación de la mujer en la publicidad, pide que los pactos y convenios internacionales se traduzcan en normas jurídicas y que se combatan los estereotipos sexistas y degradantes de la mujer. 
y aludiendo a su disponibilidad; el uso del estereotipo de la mujer ama de casa ha disminuido, pero sigue presente en muchos anuncios publicitarios; la mujer aparece con frecuencia en actitud pasiva, de sumisión o subordinación al hombre; se consagra el estereotipo de la «mujer 10», un modelo de mujer excesivamente preocupada por su físico, o de la «supermujer», que trabaja, se ocupa de la casa y cuida su imagen; y, por último, la diferencia de roles y mensajes sigue estando presente en la publicidad infantil ${ }^{18}$.

En este sentido, es cierto que el nivel de sensibilización de la sociedad española por el tratamiento estereotipado de la mujer en la publicidad ha aumentado, y es cada vez es mayor la preocupación por modificar la imagen publicitaria de la mujer, aunque las dificultades para ello son grandes, ya que es preciso transformar las bases de la actividad publicitaria ${ }^{19}$.

\subsubsection{Las normas sobre publicidad discriminatoria o denigrante}

En relación a la publicidad, la intervención del legislador y de los propios afectados se ha traducido en la aprobación de los siguientes textos normativos.

a) La Ley General de Publicidad

Las normas generales relativas a la protección de la imagen de la mujer en la publicidad se encuentran, en primer lugar, en la Ley General de Publicidad, de acuerdo con la cual, es ilícita la publicidad que atente contra la dignidad de la persona o vulnere los valores y derechos reconocidos en la Constitución, especialmente en lo que se refiere a la infancia, la juventud y la mujer ${ }^{20}$. Esta disposición de carácter general se demostró poco eficaz en la práctica, porque no aportaba elementos concretos que permitieran al operador jurídico determinar en qué casos un anuncio publicitario vulneraba la dignidad y los derechos de la mujer, porque le otorgaban un margen de apreciación muy amplio, con lo que, como luego veremos, en caso de duda, no se consideraba que la publicidad fuese sexista o discriminatoria.

A superar este problema ha contribuido decisivamente la LO 1/2004 de protección integral contra la Violencia de Género, que añadió a la redacción de la Ley de Publicidad un párrafo más en el que especificaba qué tipo de anuncios debían considerarse publicidad discriminatoria o denigrante: «los

18. Datos recogidos en los informes o memorias que anualmente publican los Observatorios de la Publicidad, concretamente, de las Memorias del Observatorio de la Publicidad del Instituto de la Mujer, emitidas desde 1999.

19. Véase, al respecto, BALAGUER, $\mathrm{M}^{a}$ Luisa: «La regulación y el control de la publicidad...», op. cit., p. 146 y ss.

20. Art. 3 de la Ley 34/1988, de 11 de noviembre, General de Publicidad en su redacción original.

Feminismo/s 12, diciembre 2008, pp. 185-202 
anuncios que presenten a las mujeres de forma vejatoria, bien utilizando particular y directamente su cuerpo o partes del mismo como mero objeto desvinculado del producto que se pretende promocionar, bien su imagen asociada a comportamientos estereotipados que vulneren los fundamentos de nuestro ordenamiento coadyuvando a generar la violencia a que se refiere la Ley Orgánica de medidas de protección integral contra la violencia de género ${ }^{21}$. Como luego veremos, esta modificación ha tenido importantes consecuencias prácticas, porque ha proporcionado elementos de juicio para determinar cuándo un anuncio publicitario es contrario a la dignidad y derechos de la mujer.

b) El Código de Conducta publicitaria

Ante la ineficacia de las normas generales sobre publicidad, en 1996 anunciantes, agencias, medios de comunicación y empresas del sector decidieron constituir la Asociación de Autocontrol de la Publicidad y firmar un Código de Conducta Publicitaria, que todos ellos se obligaban a cumplir ${ }^{22}$. Dicho Código se ocupa también de la publicidad discriminatoria y establece que: «la publicidad no sugerirá circunstancias de discriminación, ya sea por razón de raza, nacionalidad, religión, sexo u orientación sexual, ni atentará contra la dignidad de persona», y que «la publicidad ha de respetar necesariamente los derechos al honor, a la intimidad y a la propia imagen ${ }^{23}$.

c) Normas de publicidad sectoriales

En relación a la publicidad en radio y televisión existen, además, normas específicas del sector. En primer lugar, el art. 8.1 de la Ley de Televisión sin Fronteras establece que, además de las formas de publicidad indicadas en el art. 3 de la Ley General de Publicidad, es ilícita, en todo caso, «la publicidad por televisión y la televenta que atenten al debido respeto a la dignidad de las personas o las discriminen por razón de sexo» y, después de la modificación introducida por la Ley de Igualdad, añade que «la publicidad o la televenta dirigidas a menores deberá transmitir una imagen igualitaria, plural y no estereotipada de mujeres y hombres» ${ }^{24}$. En segundo lugar, las disposiciones que, en ese mismo sentido, introducen las Leyes de igualdad y las Leyes contra la

21. Disp. Adic. $6^{a} .1$ de la LO 1/2004, de 28 de diciembre, de medidas de protección integral contra la violencia de género.

22. Más información en www.autocontrol.es.

23. Normas deontológicas 10 y 11 del Código de Conducta Publicitaria aprobado el 3 de abril de 2002.

24. Ley 25/1994, de 12 de julio, de incorporación de la Directiva 89/552/CEE sobre coordinación de disposiciones legales, reglamentarias y administrativas de los Estados miembros relativas al ejercicio de actividades de radiodifusión televisiva, modificada por la Ley 22/1999, de 7 de junio. 
violencia de género aprobadas en numerosas Comunidades Autónomas ${ }^{25}$. Y, finalmente, las normas internas que aprueban las propias radiotelevisiones públicas, que suelen incluir una disposición en la que se prohíbe la contratación de publicidad discriminatoria o degradante ${ }^{26}$.

Por otro lado, también hay que citar las normas sobre publicidad institucional aprobadas por diversos entes públicos. Con carácter general, estas leyes establecen que la actividad publicitaria de la Administración Pública correspondiente deberá desarrollarse con respeto a los principios de igualdad y no discriminación por razón de sexo, defensa de la dignidad de la persona y de los derechos al honor, intimidad y propia imagen, con especial atención a la imagen de la mujer ${ }^{27}$.

\subsubsection{El control del cumplimiento de las normas sobre publicidad discriminatoria}

Una vez establecido por ley que la publicidad no puede transmitir una imagen discriminatoria o denigrante de la mujer, es preciso analizar las vías que existen para reaccionar en el caso de que, incumpliendo la ley, se emita publicidad de ese tipo, y, sobre todo, analizar de qué forma razonan los órganos competentes para decidir si un anuncio publicitario es, o no, discriminatorio.

a) Los jueces y tribunales ordinarios

Contra la publicidad que se considere ilícita por discriminatoria, en el sentido establecido en la Ley de Publicidad, cabe presentar una «acción de cesación y rectificación», mediante la cual se puede solicitar la cesación y/o la corrección del anuncio, primero, al anunciante, y, posteriormente, en caso de que éste no cese o rectifique, al órgano de la jurisdicción ordinaria corres-

25. Art. 26. 2 de la Ley 4/2005, de 18 de febrero, del Parlamento Vasco, de igualdad de hombres y mujeres; art. 4.1 de la Ley 5/2005, de 20 de diciembre, del Parlamento de Madrid, de violencia domestica; art. 6.5 de la Ley 4/2007, de 22 de marzo, del Parlamento de Aragón, de protección contra la violencia de género; art. 11 de la Ley 11/2007, de 27 de julio, del Parlamento de Galicia, contra la violencia de género; art. 57.2 de la Ley 12/2007, de 26 de noviembre, del Parlamento de Andalucía, para la promoción de la igualdad de género.

26. Por ejemplo, las normas internas de publicidad aprobadas para TVE el 11 de enero de 2001 prohíben la discriminación por razón de sexo en los anuncios (norma 6).

27. Art. 4 de la Ley 4/99 de la Junta de Andalucía sobre actividad publicitaria de la Administración Pública andaluza; art. 4.1de la Ley 16/2003 de las Cortes de Aragón, sobre publicidad institucional; art. 5.1 de la Ley 7/2003, de las Cortes Valencianas, de publicidad institucional; y art. 4 de la Ley 18/2000, del Parlamento de Cataluña, de publicidad institucional.

Feminismo/s 12, diciembre 2008, pp. 185-202 
pondiente ${ }^{28}$. Por otro lado, a instancia del demandante, el Juez, cuando lo crea conveniente, incluso en el caso de no haberse consumado el perjuicio, podrá, con carácter cautelar, ordenar la cesación provisional de la publicidad o prohibir su difusión ${ }^{29}$. La sentencia estimatoria del Juez podrá conceder al anunciante un plazo para que suprima los elementos ilícitos u ordenar la cesación o prohibición definitiva de la publicidad ${ }^{30}$. Además, el ejercicio de las acciones descritas es compatible con el ejercicio de las acciones civiles, penales, administrativas o de otro orden que correspondan ${ }^{31}$.

Especialmente importante es la amplia legitimación activa, ya que son numerosas las personas que pueden solicitar del anunciante la cesación o rectificación: la Delegación Especial del Gobierno contra la Violencia sobre la mujer, el Instituto de la mujer o su equivalente en el ámbito autonómico, las asociaciones legalmente constituidas que tengan como objetivo único la defensa de los intereses de la mujer y no incluyan como asociados a personas jurídicas con ánimo de lucro, así como a los titulares de un derecho o interés legítimo ${ }^{32}$. Posteriormente, pueden presentar la «acción de cesación» ante los órganos judiciales competentes, además del Ministerio Fiscal, todas las personas e instituciones anteriormente citadas ${ }^{33}$.

A pesar de las posibilidades que ofrece la Ley General de Publicidad, son escasísimas las demandas presentadas por publicidad discriminatoria o denigrante. A las dificultades que entraña iniciar un proceso judicial (necesidad de asistencia jurídica profesional, costes económicos...) se une la relativa satisfacción que se puede obtener a través del mismo, ya que no resulta fácil obtener una decisión favorable. Por ese motivo no puede hablarse de jurisprudencia sobre el tema. No obstante, hay que hacer referencia a una de las pocas sentencias sobre publicidad discriminatoria, la sentencia de 3 de marzo de 1992 del Juzgado de Primera Instancia e Instrucción de Ibi (Alicante) ${ }^{34}$.

28. Previamente es preciso haber solicitado al propio anunciante la cesación o corrección de la publicidad, y, sólo en los casos de silencio o negativa, se podrán ejercer las acciones judiciales (arts. 25-26 de la Ley General de Publicidad). El procedimiento se regula en la propia Ley General de Publicidad, en su art. 29.

29. Art. 30 de la Ley General de Publicidad.

30. Esta es la medida protectora adoptada por el juez normalmente, aunque también cabe la de rectificar la publicidad (art. 31 de la Ley General de Publicidad).

31. Art. 32 de la Ley General de Publicidad.

32. Art. 25.1.bis de la Ley General de Publicidad, introducido por la Ley Orgánica 1/2004, de 28 de diciembre, de medidas de protección integral contra la violencia de género.

33. Disposición adicional de la Ley General de Publicidad, introducida por la Ley Orgánica 1/2004, de 28 de diciembre, de medidas de protección integral contra la violencia de género.

34. Esta sentencia puede consultarse en Actualidad Jurídica Aranzadi, n 47, 1992, p. 9. 
En esta sentencia se declara ilegal, por sexista y discriminatorio, un anuncio de juguetes en el que se distinguían los dirigidos a los niños (una oferta de juguetes amplia, relacionada con el mundo exterior y las profesiones) y los dirigidos a las niñas (muñecas y utensilios para la casa y la cocina). Para llegar a esta conclusión, el Juez razonó que, dada la falta de concreción del art. 3 de la Ley General de Publicidad (en su redacción original), que se limitaba a referirse a los valores y principios contenidos en la Constitución, era necesario acudir a los Tratados y Convenios Internacionales firmados por España, tal y como dispone el art. 10.2 CE. En este caso, en opinión del juez, resultaba de aplicación la «Convención de la ONU sobre la eliminación de todas las formas de discriminación contra la mujer», en la que se califica como discriminación de la mujer «toda distinción basada en el sexo que tenga por objeto o por resultado menoscabar o anular el reconocimiento goce o ejercicio por la mujer de los derechos y libertades fundamentales en las esferas políticas, económicas, social, cultural y civil o en cualquier otra esfera», y en la que los Estados se comprometen a «tomar las medidas apropiadas para modificar los patrones socioculturales de conducta de hombres y mujeres con miras a eliminar los prejuicios y prácticas consuetudinarias basadas en la idea de inferioridad o superioridad de cualquiera de los sexos o en funciones estereotipadas de hombres y mujeres».

b) El Jurado de la Publicidad

En el ámbito del Código de Conducta Publicitaria, al que antes nos hemos referido, funciona el Jurado de la Publicidad, órgano creado por la misma Asociación de Autocontrol de la Publicidad como vía alternativa para la solución de conflictos. De este modo, cualquiera que considere discriminatorio o denigrante un anuncio del que sea responsable alguno de los asociados, puede presentar una reclamación ante el Jurado de la Publicidad, es decir, existe también en este caso una amplia legitimación activa, como demuestran las reclamaciones que se presentan, muchas de ellas firmadas por asociaciones y particulares. Las resoluciones del Jurado tienen eficacia no sólo entre las partes, sino que también vinculan a los demás asociados y son decisiones de arbitraje, por lo que el posible el recurso posterior ante los tribunales ordinarios ${ }^{35}$.

Aquí sí podemos encontrar una relevante línea interpretativa sobre la imagen de la mujer en la publicidad, ya que, desde que comenzó a funcionar el Jurado de la Publicidad, en julio de 1996, se ha demostrado una vía ágil y realmente alternativa para la solución de conflictos, resolviendo un elevado porcentaje de demandas en el sector.

35. Normas.I.4 a I.7 del Código de Conducta Publicitaria (www.autocontrol.es).

Feminismo/s 12, diciembre 2008, pp. 185-202 
La interpretación que ha realizado el Jurado de la Publicidad en esta materia se puede resumir del siguiente modo:

- Con carácter general, el Jurado de la Publicidad reconoce que en una sociedad como la española, plural, abierta, moderna, tolerante, y con disparidad de criterios, donde la consideración de «sexista» puede ser muy subjetiva, resulta difícil pronunciarse sobre el tratamiento de la mujer en la publicidad, lograr un consenso sobre el carácter sexista o no de un anuncio, es decir, lograr una decisión objetiva ${ }^{36}$.

- El Jurado ha ido estableciendo una serie de criterios para determinar cuándo un anuncio puede considerarse discriminatorio o sexista, pero, a pesar de ello, hay muchos casos en los que el Jurado no es capaz de determinar si un anuncio concreto supone un atentado contra la dignidad de la mujer y, después de expresar sus dudas, aplica el principio indubio pro libertate, es decir, en caso de duda, resuelve a favor de la libertad del anunciante ${ }^{37}$.

- En cuanto a los citados criterios, en una primera etapa (desde las primeras decisiones hasta la aprobación de la LO contra la Violencia de Género), el Jurado ha realizado una interpretación bastante permisiva cuyos principales criterios han sido los siguientes:

- En relación con la utilización de la mujer en la publicidad, el Jurado afirma que «la simple representación publicitaria del cuerpo humano no puede entenderse como un atentado contra la dignidad de las personas». «España se asienta sobre una sociedad muy plural, moderna, abierta y tolerante, en la que la simple representación del cuerpo humano pueda entender por sí misma como un atentado contra la dignidad». Además, entiende que «el rechazo generalizado de la simple utilización del cuerpo humano supondría un claro atentado a la libertad de expresión del anunciante». Se podría hablar de un atentado contra la dignidad, en cambio, «cuando por otras circunstancias ajenas a la pura y simple representación del cuerpo humano se pudiese entender que el mensaje publicitario atenta contra derechos fundamentales de la mujer, bien haciéndola aparecer como un simple objeto de satisfacción sexual a disposición del hombre, bien relegándola a un papel secundario en nuestra sociedad mediante la utilización de mensajes discriminatorios direc-

36. Caso Prenatal S.A, Resolución de 6 de febrero de 1997, punto IV.1. Desde entonces, así se reitera prácticamente en todas las resoluciones sobre la materia.

37. Por ejemplo, Caso Ron Barceló II, Resolución de 29 de abril de 2003. 
tos o implícitos $»^{38}$, así como haciéndola aparecer «en actitud de sometimiento o de inferioridad $»^{39}$.

- De acuerdo con lo anterior, en relación con la utilización de desnudos femeninos, totales o parciales, el Jurado admite «no tener reparos frente al grafismo público del cuerpo humano, cuando se valora su armonía o su estética». La utilización sexista del desnudo se produce de la interrelación entre éste, que por sí solo no es rechazable, y el eslogan del anuncio, cuando la utilización del cuerpo femenino no tiene nada que ver con el mensaje que se pretende transmitir. Es claro que pueden existir todo tipo de interpretaciones sobre la relación entre el desnudo y el eslogan o el mensaje, pero «cuando caben interpretaciones que puedan ofender a la dignidad de la mujer, no debe apreciarse el beneficio de la duda» y debe considerarse sexista ${ }^{40}$. En otras ocasiones, nos encontraremos «ante una imagen clara y coherente con el mensaje pretendido, por lo que parece poco adecuado intentar encontrar otros significados, difíciles de percibir» ${ }^{41}$. El «uso moderado del desnudo humano, siempre y cuando se sustente en una serie de valores estéticos, esté en consonancia y armonía con el resto del anuncio, carezca de connotaciones morbosas y no resulte procaz u obsceno», no lo considera el Jurado contrario a la dignidad de la mujer, ni discriminatorio ${ }^{42}$.

- Para determinar si la imagen del cuerpo de la mujer se utiliza como reclamo, el Jurado ha tenido en cuenta el «público objetivo» del anuncio. Así, en algún caso, como un anuncio de tiendas de premamá, el Jurado consideró que el público objetivo era la mujer joven embarazada, por lo que el uso de un desnudo no podía considerarse publicidad machista ${ }^{43}$.

- El Jurado de la Publicidad ha considerado discriminatorios los anuncios que «claramente den a entender que existen ciertos productos cuyo uso o consumo debería quedar exclusivamente reservado a los hombres en razón de su masculinidad, promoviendo con ello un diferente posicionamiento social hombre-mujer basado exclusivamente en razones de género», diferenciando

38. Caso Bardinet S.A, Resolución de 30 de octubre de 1997, punto 3. También Caso Colonia Jacq‘s, Resolución de 3 de febrero de 1999, punto II.3.

39. Caso Barceló \& Co, Resolución de 26 de noviembre de 1997, y Recurso de alzada de 29 de enero de 1998; también, Caso Chicco Española, Resolución de 12 de junio de 1998; y Caso Bacardi-Martini, Resolución de 24 de noviembre de 1997, y Recurso de alzada de 29 de enero de 1998.

40. Caso Virgin Express, Resolución de 20 de octubre de 1996. También, Caso Relojes Promaster, Resolución de 29 de julio de 1999; Caso Et cobrim de moda, Resolución de 7 de febrero de 2000; y Caso París, Resolución de 4 de junio de 2001.

41. Caso Prenatal S.A, Resolución de 6 de febrero de 1997.

42. Caso Como2, Resolución de 19 de diciembre de 2000.

43. Caso Prenatal S.A, Resolución de 6 de febrero de 1997.

Feminismo/s 12, diciembre 2008, pp. 185-202 
así entre los anuncios dirigidos a un público masculino o femenino y en los que simplemente se indica para quién está diseñado inicialmente el producto, de aquellos otros discriminatorios, que, traspasando este límite, inciden en la idea de exclusión, presentando un producto como exclusivo de los hombres y absolutamente vetado para las mujeres ${ }^{44}$.

- La aprobación de la LO contra la Violencia de Género marca el inicio de una segunda etapa en la interpretación que el Jurado realiza de la publicidad discriminatoria. Los dos nuevos elementos de juicio que introduce esta Ley, y a los que antes hemos hecho referencia, han servido al Jurado para establecer criterios más concretos y realizar una interpretación menos permisiva. Esos dos elementos han sido concretados por el Jurado del siguiente modo:

- El uso del cuerpo femenino es ilícito cuando se usa como «mero objeto desvinculado del producto» y eso sucede siempre que se dan los siguientes requisitos: a) que el cuerpo sea la "parte captatoria del mensaje», que la imagen del cuerpo constituya el elemento principal o protagonista y que, por sus características, atraiga en mayor medida la atención de los destinatarios; b) que el uso del cuerpo sea «decorativo», como mero objeto para atraer la atención, pero sin que desempeñe ningún rol activo en la acción publicitaria ni guarde conexión con el argumento publicitario; y c) que no exista conexión entre la imagen femenina y el producto promocionado ${ }^{45}$. La concreción de estos tres requisitos permite considerar discriminatorios o sexistas a un altísimo número de anuncios en los que la imagen de la mujer se utiliza como reclamo publicitario. Por ello, por ejemplo, un conocido anuncio de Ron Barceló que se emite desde 1996 y cuya licitud fue confirmada por el Jurado en su primera etapa, en esta segunda fue considerado ilícito aplicando los criterios anteriores $^{46}$.

- En segundo lugar, el Jurado considera que son ilícitas todas las imágenes asociadas a comportamientos estereotipados que contribuyan a generar violencia de género. Y para ello el Jurado utiliza el «principio de responsabilidad social de la comunicación comercial», recogido en el Code of Advertising and Marketing Communication Practice de la Cámara de Comercio Internacional, que dispone que toda comunicación comercial debe elaborarse con el debido sentido de la responsabilidad social y profesional. Por eso, ante el grave

44. Caso Reloj IWC, Resoluciones de 1 de junio de 2000 y de 24 de febrero de 2003; Caso Internacional de Relojería S.A., Resolución de 14 de enero de 2004.

45. Caso Mágnum, Resolución de 15 de diciembre de 2005; Caso Media Markt Saturn, Resolución de 7 de junio de 2006; Caso Air Berlin, Resolución de 20 de junio de 2006 Caso SEAT León, Resolución de 8 de enero de 2007.

46. Caso Ron Barceló, Recurso de Alzaga, Resolución de 26 de enero de 2006. 
problema de la violencia de género que existe actualmente, y contra el que están reaccionando todos los poderes públicos, utilizar como reclamo publicitario determinadas escenas que contribuyan a generar ese tipo de violencia, como, por ejemplo, «una escena de sometimiento sexual de la mujer contra su voluntad», debe considerarse contrario a dicho principio ${ }^{47}$.

c) Otros organismos de control

Finalmente, al margen del control jurisdiccional, resulta determinante la labor de supervisión que puedan realizar otro tipo de organismos, como los Observatorios de Publicidad y los Consejos Audiovisuales.

En cuanto a los primeros, el Observatorio de la Publicidad sobre contenidos sexistas, que funciona en el seno del Instituto de la Mujer ${ }^{48}$, así como los Observatorios de publicidad que funcionan en diversas Comunidades Autónomas $^{49}$, están realizando una labor fundamental. Reciben reclamaciones de anuncios que atenten contra la dignidad de la mujer, solicitan su rectificación o modificación, y, sobre todo, realizan una labor determinante de sensibilización, concienciación y denuncia, asumiendo cada vez más competencias para todo ello. El fortalecimiento de los mecanismos de control de la publicidad discriminatoria pasa, desde luego, por reconocer y apoyar la labor de estos Observatorios.

En cuanto a los Consejos Audiovisuales, que sólo existen aún en Cataluña, Navarra y Andalucía, pueden disponer el cese o rectificación de las emisiones de publicidad, reciben quejas y reclamaciones, y emiten informes y recomendaciones, aunque hasta ahora su labor ha sido muy limitada ${ }^{50}$.

47. Caso Dolce\&Gabbana, Resolución de 2 de marzo de 2007.

48. En 2005 el Observatorio de la Publicidad recibió 400 denuncias por publicidad discriminatoria. El medio más denunciado es la televisión, que ha emitido este último año el $59,9 \%$ de los anuncios denunciados. Y las denuncias más numerosas se refieren al uso sexista de la imagen de la mujer (datos de las Memorias anuales del Observatorio de la Publicidad, en www.migualdad.es/mujer/medios/publicidad/observatorio.htm).

49. Por ejemplo, el Observatorio andaluz de la Publicidad no sexista (www.iam-publicidad.org) y el Observatorio de Publicidad y Comunicación Sexista, dependiente del Instituto Canario de la Mujer (www.icmujer.org/011obs.htm).

50. Art. 7.1 de la Ley 18/2001, de 5 de julio, de actividad audiovisual en Navarra; arts. 4, 7 y 15 de la Ley 1/2004, de 17 de diciembre, del Parlamento de Andalucía, de actividad audiovisual y del Consejo Audiovisual, junto a las disposiciones de la Ley 12/2007, de igualdad, y de la Ley 13/2007, contra la violencia de género, que refuerzan su actuación en este ámbito; y art.10 de la Ley 2/2000, de 4 de mayo, del Parlamento de Cataluña, de regulación del Consejo Audiovisual, junto a los arts. 92, 132, 133 y 136 de la Ley 22/2005, de 29 de diciembre, de comunicación audiovisual de Cataluña, en los que se regula las sanciones por incumplimiento de las normas de publicidad.

Feminismo/s 12, diciembre 2008, pp. 185-202 